\title{
Natural Radioactivity at an Uraniferous Site
}

\author{
${ }^{1}$ Claudio de Carvalho Conti, \\ ${ }^{2}$ Esau Francisco Sena Santos and ${ }^{1}$ Isabel Cristina Poquet Salinas \\ ${ }^{1}$ Institute for Radioprotection and Dosimetry-IRD/CNEN, Radioprotection Division, \\ Salvador Allende Avenue, s/no, P.O. Box 37750, CEP 22783-127, Barra da Tijuca, Rio de Janeiro, Brazil \\ ${ }^{2}$ National Observatory-ON/CNPq, General Jose Cristino Avenue, 77, CEP 20921-400, Rio de Janeiro, RJ, Brazil
}

Received 2012-09-05, Revised 2013-01-03; Accepted 2013-02-14

\begin{abstract}
The aim of this study is to evaluate the soil composition, the radioactive isotopes concentration and the outdoor air Kerma in the region of the Uraniferous Province of Lagoa Real, Bahia State, located at northeast of Brazil. It has used data from an airborne gamma-ray survey previously carried out in the region, namely Projeto Sao Timoteo and computer simulations of the soil and radiation transport by the Monte Carlo method. The simulation, considering environmental characteristics, mainly soil chemical composition and density, provide means to evaluate the air Kerma rate due to radionuclides present in the different types of soils. The evaluation was carried out considering the main contributors to the terrestrial natural radioactivity: ${ }^{40} \mathrm{~K}$ and the isotopes of the radioactive series of ${ }^{238} \mathrm{U}$ and ${ }^{232} \mathrm{Th}$. In radiometric studies used to quantify exposure to natural radioactivity, a normal trend showed that regions with high values of the surface distribution of radionuclides had the highest values of air Kerma. The highest value was found for soil type LVe1 (146.40 nGy.h ${ }^{-1}$ average, ranging from $23.97 \mathrm{nGy} \cdot \mathrm{h}^{-1}$ to $450.62 \mathrm{nGy} \cdot \mathrm{h}^{-1}$ ), this type of soil and most of the anomalies located in this region, being rich in silica minerals, is of granitic rocks type.
\end{abstract}

Keywords: Natural Radioactivity, Monte Carlo, Air Kerma, Airborne Gamma-Ray Survey

\section{INTRODUCTION}

The Province of Lagoa Real is located in southcentral portion of the state of Bahia in the northeastern region of Brazil, as shown in Fig. 1. There are, in this area, thirty three uraniferous anomalies which were identified during an airborne gamma-ray survey, as part of a project called Projeto São Timóteo held in 1979.

The distribution map of the surface absorbed dose rate in air, obtained from the airborne gamma-ray survey by the Projeto São Timóteo is shown in Fig. 2. The average absorbed dose in air was $61.08 \mathrm{nGy} \cdot \mathrm{h}^{-\mathrm{P}}$, whereas the highest values are related to the central region of the map. According to Lobato et al. (1982) and Maruejol et al. (1987) this region is composed essentially of granitic soil and, in its entirety, is composed of minerals rich in silica (albite, biotite, quartz). Dickson and Scott (1997) and IAEA (2003) say that, in such a case, the soil has a high content of K, U and Th. On the other hand, the soils surrounding the province are derived from geologies impoverished in silica, which is composed of basic rocks and ultra-basic and, hence, present depleted levels of $\mathrm{K}, \mathrm{U}$ and $\mathrm{Th}$.
The radioactivity in a given soil is directly related to radioactive material present in its composition due to processes occurred during its formation. The airborne gamma-ray survey reflects the geochemical variation of $\mathrm{K}, \mathrm{U}$ and Th from the top $50 \mathrm{~cm}$ of the surface of the Earth (IAEA, 2003). Therefore, this study was based on the fact that these features were preserved according to a geological/pedological study of the Brazilian Agricultural Research CorporationEMBRAPA (1979). The soil map of the province shown in Fig. 3 shows the uraniferous anomalies.

Computational simulation must be representative of the actual scenario, hence, it was considered in the simulation the soil composition of the Uraniferous Province of Lagoa Real to calculate the air Kerma. The soil's density used for the simulation was $1.8 \mathrm{~g} . \mathrm{cm}^{-3}$, based on EMBRAPA (1979). The classification of four types of soil in the province also followed the pattern of EMBRAPA (1979), which were characterized as: LVe1 (latosol eutrophic red/yellow), LVe5 (latosol eutrophic red/yellow type A), LVd13 (latosol dystrophic red/yellow type A) and PE34 (podzolic red/yellow, equivalent eutrophic).

Corresponding Author: Claudio de Carvalho Conti, Institute for Radioprotection and Dosimetry-IRD/CNEN, Radioprotection Division Salvador Allende Avenue, s/no, P.O. Box 37750, CEP 22783-127, Barra da Tijuca, Rio de Janeiro, Brazil 


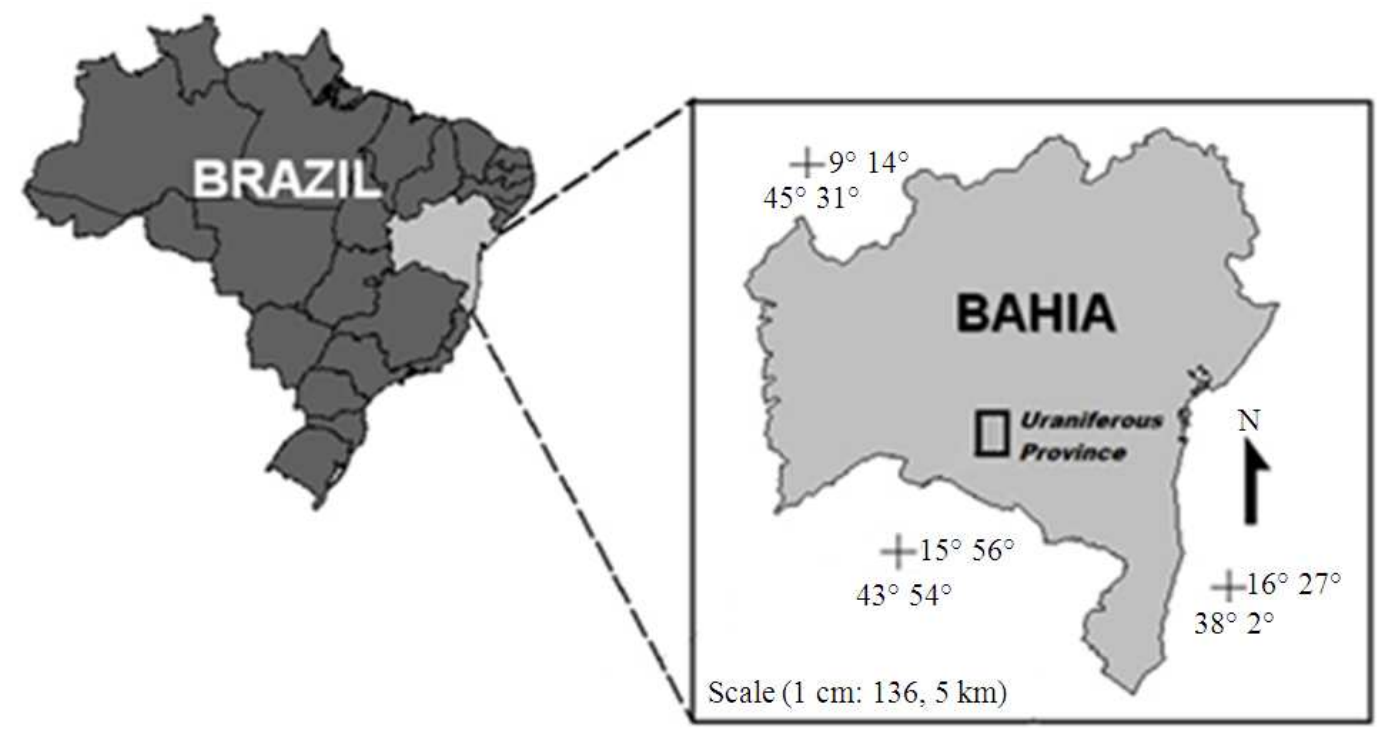

Fig. 1. Area of the Uraniferous Province of Lagoa Real

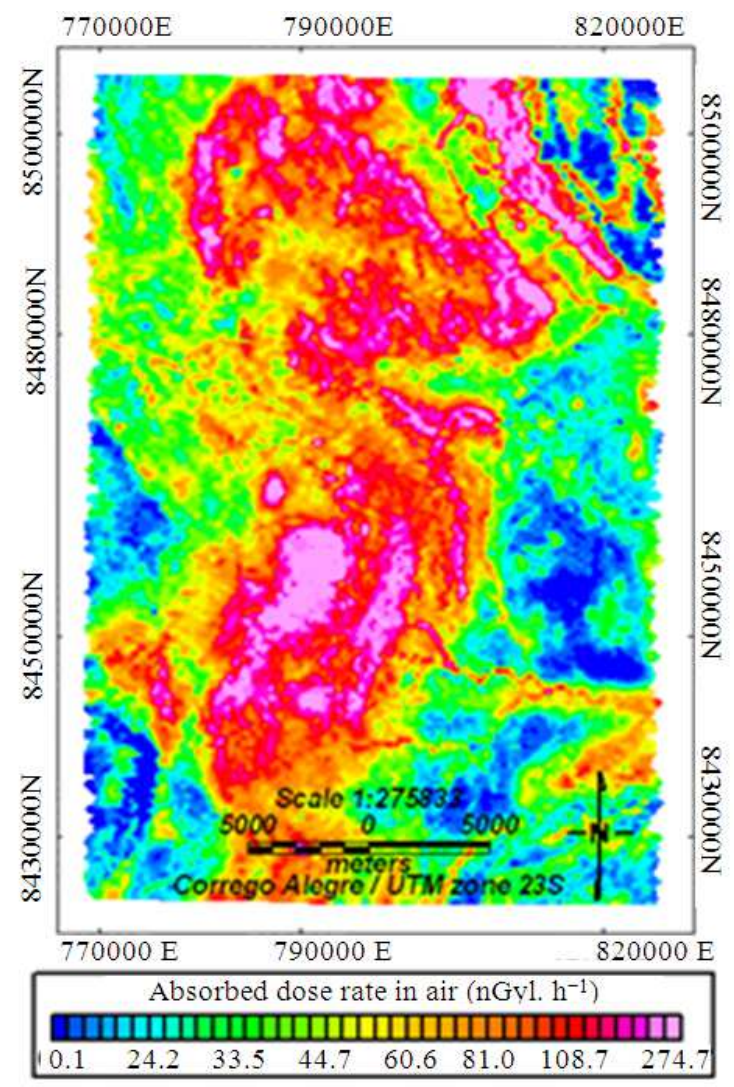

Fig. 2. Distribution of the absorbed dose rate in air in the studied area

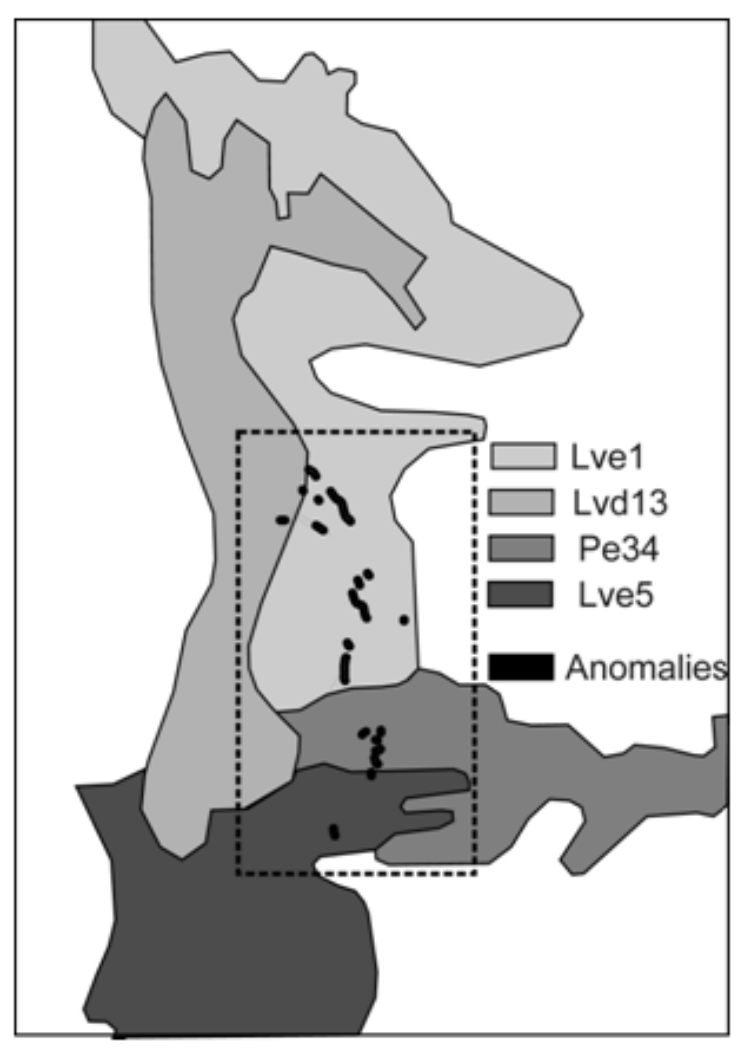

Fig. 3. Soil map of the Uraniferous Province of Lego Real (EMBRAPA, 1979) 
Table 1. Chemical composition of soil used for the simulation

\begin{tabular}{lr}
\hline Element & \multicolumn{1}{c}{$(\%)$} \\
\hline $\mathrm{H}$ & 0,0589 \\
$\mathrm{C}$ & - \\
$\mathrm{O}$ & 48,5853 \\
$\mathrm{Na}$ & 2,2852 \\
$\mathrm{Mg}$ & 0,3135 \\
$\mathrm{Al}$ & 7,3351 \\
$\mathrm{Si}$ & 33,6924 \\
$\mathrm{P}$ & 0,0785 \\
$\mathrm{~K}$ & 4,5326 \\
$\mathrm{Ca}$ & 0,9507 \\
$\mathrm{Ti}$ & 0,2218 \\
$\mathrm{Mn}$ & 0,0465 \\
$\mathrm{Fe}$ & 1,8996 \\
\hline
\end{tabular}

Soil type LVe1 covers most of the province and it is the pattern of a granitic geological origin, where most of the uranium anomalies are found in the region. Furthermore, soil type PE34, for example, which has the smallest levels of anomalies, is related to basic rock and ultrabasic. Table 1 shows the chemical composition of soils used for the simulation and Table $\mathbf{2}$ shows the concentration of $\mathrm{K}, \mathrm{U}$ and $\mathrm{Th}$ in the four soil types encountered in the province.

This study uses the MCNP5 Monte Carlo computer code for the simulationsin order to derive conversion factors from soil concentration of natural radioactivity to air Kerma rate. The radionuclides concentrations in the soil were taken from the airborne gamma-ray survey data previously held in the same area, namely Projeto São Timóteo.

Finally, the results of this study serve as a parameter in the assessment of the radiological risk, since this area contains a surrounding population of about 173.145 inhabitants. The production of energy must be conducted in a safe manner for the environment, including humans and biota and be aware that the mining industries may generate large amount of Naturally Occurring Radioactive Material (NORM).

\section{MATERIALS AND METHODS}

Monte Carlo methods have been widely used for exposure calculation (Clouvas et al., 2000; Conti et al., 1999; Jacob and Paretzke, 1987; Meckbach et al., 1996; Salinas et al., 2006a; 2006b; 2007; LANL, 2003) and have also been used in this study to perform the radiation transport calculation.

The geometry considered was a $400 \mathrm{~m}$ radius open field, without any surrounding construction; a $50 \mathrm{~cm}$ layer of soil of $1.8 \mathrm{~g} . \mathrm{cm}^{-3}$ density and chemical composition according to the its type and; a 200 m layer of air of $1.205 \mathrm{E}-3$ g.cm ${ }^{-3}$ density above ground to account for scattering. The detection region consists of an air filled sphere with a radius of $50 \mathrm{~cm}$, centered at $1 \mathrm{~m}$ above the soil-air interface.

As this study aims the determination of the air Kerma in an open space, the source consists of gamma rays emitted isotropically due to radioactive material distributed homogeneously in the ground. The photons were discarded only beyond the region of interest.

The results from the computational calculation by Monte Carlo method are the score of the energy fluence density over the detection region. The energy fluence density is then multiplied by the energy transfer coefficient (Nowotny, 1998) and integrated over the energy range in order to calculate the air Kerma by Equation 1 (ICRUM, 1980):

$\mathrm{K}=\varnothing\left[\mathrm{E}\left(\mu_{\mathrm{tr}} / \rho\right)_{\text {air }}\right]$

where, " $K$ " is the air Kerma; " $\varnothing "$ "is the energy fluencedensity over the sphere surface; " $E$ " is the photon energy and " $\left(\mu_{\mathrm{tr}} / \rho\right)_{\text {air }}$ " is the mass energy transfer coefficient for air (Nowotny, 1998).

Conversion factors from soil concentration to air Kerma were determined for 50, 500, 1000, 2000 and $3000 \mathrm{KeV}$ as shown in Table 3. The obtained curve was used to calculate de conversion factors in the energy range of the natural gamma emitters for the geometry described previously. The curve was plotted and fitted by Equation 2.

$y=41.6 x-1659$

where, $y$ is the outdoorair Kerma in Gy/Bq.s.m ${ }^{-3}$ and " $x$ " is the photon energy in $\mathrm{KeV}$.

The results were compared to the values calculated by Eckerman and Ryman (1993), which were calculated for a similar geometry, but different chemical composition and density of the soil, also shown in Table 3.

Table 2 Concentration of ${ }^{40} \mathrm{~K},{ }^{238} \mathrm{U}$ and ${ }^{232} \mathrm{Th}$ series in the four soil types studied in the Uraniferous Province of Lagoa.

It is possible to observe a similar pattern, with the air Kerma values increasing with energy in a similar manner. Although the results are very close, this study's values are lower with a difference of up to $16 \%$, which is due to the differences in the soil density and chemical composition. 
Table 2. Concentration of ${ }^{40} \mathrm{~K},{ }^{238} \mathrm{U}$ and ${ }^{232} \mathrm{Th}$ series in the four soil types studied in the Uraniferous Province of Lagoa Real Projeto São Timóteo, 1979

\begin{tabular}{llll}
\hline & Average (Min.-Max.) in Bq.Kg & & \\
Soil & Potassium & Uranium & Thorium \\
\hline PE34 & $528,97(37,56-2065,80)$ & $32,11(3,21-120,91)$ & $59,72(6,90-280,83)$ \\
LVe1 & $845,97(78,25-1871,74)$ & $68,79(13,71-285,53)$ & $139,06(25,01-421,27)$ \\
LVd13 & $610,35(50,08-1777,84)$ & $51,87(9,51-204,52)$ & $107,39(18,55-366,13)$ \\
LVe5 & $732,42(59,47-2169,09)$ & $51,99(8,27-198,22)$ & $101,09(15,23-345,14)$ \\
\hline
\end{tabular}

Table 3. Values of the outdoor air Kermacalculated for different energies $(50,500,1000,2000$ and $3000 \mathrm{KeV})$

$\begin{array}{lll} & \left(\mathrm{Gy} / \mathrm{Bq} \cdot \mathrm{s} \cdot \mathrm{m}^{-3}\right) & \\ & -\mathrm{R} & \\ \text { Energy }(\mathrm{KeV}) & \text { by this work } & \text { Literature } \\ \text { (Eckerman and Ryman, 1993) }\end{array}$

Table 4. Air Kerma rates for each type of soil due to $40 \mathrm{~K}$

\begin{tabular}{|c|c|c|c|c|}
\hline \multirow[b]{2}{*}{ Potassium } & \multicolumn{4}{|c|}{$\left[\mathrm{nGy} \cdot \mathrm{h}^{-1}\right]$, Average (Min.-Max.) } \\
\hline & PE34 & LVe1 & LVd13 & LVe5 \\
\hline${ }^{40} \mathrm{~K}$ & $21,35(1,52-83,39)$ & $34,00(3,16-75,55)$ & $24,64(2,02-71,76)$ & $29,56(2,40-87,56)$ \\
\hline
\end{tabular}

Table 5. Air Kerma rates for each type of soil due to $238 \mathrm{U}$ series

\begin{tabular}{|c|c|c|c|c|}
\hline \multirow[b]{2}{*}{${ }^{238} \mathrm{U}$ series } & \multicolumn{4}{|l|}{$\left[\mathrm{nGy} \cdot \mathrm{h}^{-1}\right]$, Average (Min.-Max.) } \\
\hline & PE34 & LVe1 & LVd13 & LVe5 \\
\hline${ }^{238} \mathrm{U}$ & $1,17.10^{-4}\left(1,17.10^{-5}-4,41.10^{-4}\right)$ & $2,51.10^{-4}\left(5,00.10^{-5}-1,04.10^{-3}\right)$ & $1,89.10^{-4}\left(3,47.10^{-5}-7,46.10^{-4}\right)$ & $1,90.10^{-4}\left(3,02.10^{-5}-7,23.10^{-4}\right)$ \\
\hline${ }^{234} \mathrm{Th}$ & $3,44 \cdot 10^{-2}\left(3,44 \cdot 10^{-3}-1,30.10^{-1}\right)$ & $7,37.10^{-2}\left(1,47.10^{-2}-3,06.10^{-1}\right)$ & $5,56.10^{-2}\left(1,02.10^{-2}-2,19.10^{-1}\right)$ & $5,57 \cdot 10^{-2}\left(8,87 \cdot 10^{-3}-2,12 \cdot 10^{-1}\right)$ \\
\hline${ }^{234 \mathrm{~m}} \mathrm{~Pa}$ & $8,97.10^{-2}\left(8,97.10^{-3}-3,38 \cdot 10^{-1}\right)$ & $1,92.10^{-1}\left(3,83 \cdot 10^{-2}-7,98 \cdot 10^{-1}\right)$ & $1,45 \cdot 10^{-1}\left(2,66 \cdot 10^{-2}-5,72 \cdot 10^{-1}\right)$ & $1,45 \cdot 10^{-1}\left(2,31.10^{-2}-5,54 \cdot 10^{-1}\right)$ \\
\hline${ }^{234} \mathrm{~Pa}$ & $2,13 \cdot 10^{-2}\left(2,13 \cdot 10^{-3}-8,01 \cdot 10^{-2}\right)$ & $4,56 \cdot 10^{-2}\left(9,09 \cdot 10^{-3}-1,89 \cdot 10^{-1}\right)$ & $3,44 \cdot 10^{-2}\left(6,30 \cdot 10^{-3}-1,36 \cdot 10^{-1}\right)$ & $3,45 \cdot 10^{-2}\left(5,48 \cdot 10^{-3}-1,31 \cdot 10^{-1}\right)$ \\
\hline${ }^{234} \mathrm{U}$ & $3,79.10^{-4}\left(3,79 \cdot 10^{-5}-1,43 \cdot 10^{-3}\right)$ & $8,12 \cdot 10^{-4}\left(1,62 \cdot 10^{-4}-3,37.10^{-3}\right)$ & $6,12 \cdot 10^{-4}\left(1,12 \cdot 10^{-4}-2,41.10^{-3}\right)$ & $6,14 \cdot 10^{-4}\left(9,77 \cdot 10^{-5}-2,34 \cdot 10^{-3}\right)$ \\
\hline${ }^{230} \mathrm{Th}$ & $1,65.10^{-3}\left(1,65 \cdot 10^{-4}-6,22.10^{-3}\right)$ & $3,54 \cdot 10^{-3}\left(7,06 \cdot 10^{-4}-1,47.10^{-2}\right)$ & $2,67.10^{-3}\left(4,90.10^{-4}-1,05.10^{-2}\right)$ & $2,68.10^{-3}\left(4,26.10^{-4}-1,02.10^{-2}\right)$ \\
\hline${ }^{226} \mathrm{Ra}$ & $4,39 \cdot 10^{-2}\left(4,39 \cdot 10^{-3}-1,65 \cdot 10^{-1}\right)$ & $9,40.10^{-2}\left(1,87.10^{-2}-3,90.10^{-1}\right)$ & $7,09 \cdot 10^{-2}\left(1,30.10^{-2}-2,80.10^{-1}\right)$ & $7,11 \cdot 10^{-2}\left(1,13 \cdot 10^{-2}-2,71 \cdot 10^{-1}\right)$ \\
\hline${ }^{222} \mathrm{Rn}$ & $3,05 \cdot 10^{-3}\left(3,05 \cdot 10^{-4}-1,15 \cdot 10^{-2}\right)$ & $6,54 \cdot 10^{-3}\left(1,30 \cdot 10^{-3}-2,72 \cdot 10^{-2}\right)$ & $4,93 \cdot 10^{-3}\left(9,05 \cdot 10^{-4}-1,95 \cdot 10^{-2}\right)$ & $4,95 \cdot 10^{-3}\left(7,87 \cdot 10^{-4}-1,89 \cdot 10^{-2}\right)$ \\
\hline${ }^{214} \mathrm{~Pb}$ & $1,74.10^{0}\left(1,74.10^{-1}-6,53.10^{0}\right)$ & $3,72.10^{0}\left(7,41 \cdot 10^{-1}-1,54 \cdot 10^{1}\right)$ & $2,80.10^{0}\left(5,14.10^{-1}-1,11.10^{1}\right)$ & $2,81.10^{0}\left(4,47.10^{-1}-1,07.10^{1}\right)$ \\
\hline${ }^{214} \mathrm{Bi}$ & $1,24 \cdot 10^{1}\left(1,24 \cdot 10^{0-} 4,68 \cdot 10^{1}\right)$ & $2,66.10^{1}\left(5,30 \cdot 10^{0}-1,10.10^{2}\right)$ & $2,01.10^{1}\left(3,68.10^{0}-7,91.10\right)$ & $2,01 \cdot 10^{1}\left(3,20 \cdot 10^{0}-7,67 \cdot 10^{1}\right)$ \\
\hline${ }^{210} \mathrm{Tl}$ & $8,91.10^{-3}\left(8,91 \cdot 10^{-4}-3,35.10^{-2}\right)$ & $1,91.10^{-2}\left(3,80.10^{-3}-7,92 \cdot 10^{-2}\right)$ & $1,44 \cdot 10^{-2}\left(2,64 \cdot 10^{-3}-5,67 \cdot 10^{-2}\right)$ & $1,44.10^{-2}\left(2,30.10^{-3}-5,5.10^{-2}\right)$ \\
\hline${ }^{210} \mathrm{~Pb}$ & $2,30.10^{-3}\left(2,30.10^{-4}-8,66.10^{-3}\right)$ & $4,93 \cdot 10^{-3}\left(9,82 \cdot 10^{-4}-2,04 \cdot 10^{-2}\right)$ & $3,71 \cdot 10^{-3}\left(6,81 \cdot 10^{-4}-1,46 \cdot 10^{-2}\right)$ & $3,72 \cdot 10^{-3}\left(5,92 \cdot 10^{-4}-1,42 \cdot 10^{-2}\right)$ \\
\hline Total & $14,36(1,44-54,08)$ & $30,77(6,13-127,72)$ & $23,20(4,25-91,48)$ & $23,26(3,7-88,67)$ \\
\hline
\end{tabular}

The conversion factors from concentration to air Kerma (nGy.h ${ }^{-1} / \mathrm{Bq} \cdot \mathrm{Kg}^{-1}$ ) were calculated for ${ }^{40} \mathrm{~K}$ and radionuclides from the ${ }^{238} \mathrm{U}$ and ${ }^{232} \mathrm{Th}$ series and multiplied by the value of the concentration $\left(\mathrm{Bq} \cdot \mathrm{Kg}^{-1}\right)$ for each soil type of the Province of Lagoa Real derived from the Projeto São Timóteo data, shown in Table 2, in order to calculate the air Kerma rate outdoor $\left(n G y \cdot h^{-1}\right)$ as shown in Equation 3:

$$
\left[\mathrm{nGy}^{-1} \mathrm{~h}^{-1} \mathrm{~Bq} \cdot \mathrm{Kg}^{-1}\right] \cdot\left[\mathrm{Bq} \cdot \mathrm{Kg}^{-1}\right]=\mathrm{nGy} \cdot \mathrm{h}^{-1}
$$

\section{RESULTS}

The results for the air Kerma rates for each type of soil due to ${ }^{40} \mathrm{~K}$ is shown in Table 4 and $\mathbf{5}$ shows the contribution of each radionuclide from the ${ }^{238} \mathrm{U}$ series; Table 6 shows the contribution of each radionuclide from the ${ }^{232}$ Th series and Table 7 shows the total outdoor air Kerma rate in the Uraniferous Province of Lagoa Real.

Figure 4 shows a comparison of the average values of air Kerma over the entire surveyed area, including all types of soils and each individual soil of the hot spots studied in this study. 
Table 6. Air Kerma rates for each type of soil due to ${ }^{232} \mathrm{Th}$ series

\begin{tabular}{|c|c|c|c|c|}
\hline \multirow[b]{2}{*}{${ }^{232}$ Th Series } & \multicolumn{4}{|l|}{$\left[\mathrm{nGy} \cdot \mathrm{h}^{-1}\right]$, Average (Min.-Max.) } \\
\hline & PE34 & LVe1 & LVd13 & LVe5 \\
\hline${ }^{232} \mathrm{Th}$ & $1,45 \cdot 10^{-3}\left(1,68 \cdot 10^{-4}-6,82 \cdot 10^{-3}\right)$ & $3,38.10^{-3}\left(6,07 \cdot 10^{-4}-1,02 \cdot 10^{-2}\right)$ & $2,61 \cdot 10^{-3}\left(4,5 \cdot 10^{-4}-8,89 \cdot 10^{-3}\right)$ & $2,45.10^{-3}\left(3,70.10^{-4}-8,38.10^{-3}\right)$ \\
\hline${ }^{228} \mathrm{Ra}$ & (5) & 0 & 0 & 0 \\
\hline${ }^{228} \mathrm{Ac}$ & $1,31 \cdot 10^{1}\left(1,52 \cdot 10^{0-} 6,18 \cdot 10^{1}\right)$ & $3,06.10^{1}\left(5,5.10^{0}-9,26.10^{1}\right)$ & $2,36.10^{1}\left(4,08 \cdot 10^{0}-8,05.10^{1}\right)$ & $2,22 \cdot 10^{1}\left(3,35 \cdot 10^{0}-7,59 \cdot 10^{1}\right)$ \\
\hline${ }^{228} \mathrm{Th}$ & $2,05 \cdot 10^{-2}\left(2,36 \cdot 10^{-3}-9,62 \cdot 10^{-2}\right)$ & $4,76 \cdot 10^{-2}\left(8,57 \cdot 10^{-3}-1,44 \cdot 10^{-1}\right)$ & $3,68 \cdot 10^{-2}\left(6,36 \cdot 10^{-3}-1,25 \cdot 10^{-1}\right)$ & $3,46.10^{-2}\left(5,22.10^{-3}-1,18.10^{-1}\right)$ \\
\hline${ }^{224} \mathrm{Ra}$ & $1,28 \cdot 10^{-1}\left(1,48 \cdot 10^{-2}-6,02 \cdot 10^{-1}\right)$ & $2,98 \cdot 10^{-1}\left(5,36 \cdot 10^{-2}-9,03 \cdot 10^{-1}\right)$ & $2,30.10^{-1}\left(3,98 \cdot 10^{-2}-7,85 \cdot 10^{-1}\right)$ & $2,17 \cdot 10^{-1}\left(3,26 \cdot 10^{-2}-7,40 \cdot 10^{-1}\right)$ \\
\hline${ }^{220} \mathrm{Rn}$ & $8,92 \cdot 10^{-3}\left(1,03 \cdot 10^{-3}-4,19.10^{-2}\right)$ & $2,08.10^{-2}\left(3,73.10^{-3}-6,29.10^{-2}\right)$ & $1,60.10^{-2}\left(2,77.10^{-3}-5,47.10^{-2}\right)$ & $1,51.10^{-2}\left(2,27.10^{-3}-5,15 \cdot 10^{-2}\right)$ \\
\hline${ }^{212} \mathrm{~Pb}$ & $1,53.10^{0}\left(1,77.10^{-1}-7,18.10^{0}\right)$ & $3,56.10^{0}\left(6,40.10^{-1}-1,08.10^{1}\right)$ & $2,75 \cdot 10^{0}\left(4,75.10^{-1}-9,37.10^{0}\right)$ & $2,59.10^{0}\left(3,89.10^{-1}-8,83.10^{0}\right)$ \\
\hline${ }^{212} \mathrm{Bi}$ & $1,57.10^{0}\left(1,82 \cdot 10^{-1}-7,39 \cdot 10^{0}\right)$ & $3,66 \cdot 10^{0}\left(6,58 \cdot 10^{-1}-1,11.10^{1}\right)$ & $2,83 \cdot 10^{0}\left(4,88 \cdot 10^{-1}-9,63 \cdot 10^{0}\right)$ & $2,66.10^{0}\left(4,01.10^{-1}-9,08.10^{0}\right)$ \\
\hline${ }^{208} \mathrm{Tl}$ & $1,87.10^{1}\left(2,16.10^{0}-8,78.10^{1}\right)$ & $4,35.10^{1}\left(7,82.10^{0}-1,32.10^{2}\right)$ & $3,36.10^{1}\left(5,80.10^{0}-1,14.10^{2}\right)$ & $3,16.10^{1}\left(4,76.10^{0}-1,08.10^{2}\right)$ \\
\hline Total & $35,07(4,05-164,88)$ & $81,64(14,68-247,34)$ & $63,05(10,89-214,97)$ & $59,36(8,94-202,64)$ \\
\hline
\end{tabular}

Table 7. Total air Kerma rates for each type of soil to ${ }^{40} \mathrm{~K}+{ }^{238} \mathrm{U}$ series $+{ }^{232} \mathrm{Th}$ series

\begin{tabular}{lllr} 
& & {$\left[\mathrm{nGy} \cdot{ }^{-1}\right]$} & \\
Soil & & $-{ }^{40} \mathrm{~K}+{ }^{238} \mathrm{U}$ series ${ }^{232} \mathrm{Th}$ series $)$ & Total \\
\hline PE34 & Average & $(21,35+14,36+35,07)$ & 70,78 \\
& Min. & $(1,52+1,44+4,05)$ & 7,00 \\
LVe1 & Max. & $(83,39+54,08+164,88)$ & 302,36 \\
& Average & $(34,00+30,77+81,64)$ & 146,40 \\
& Min. & $(3,16+6,13+14,68)$ & 23,97 \\
LVd13 & Max. & $(75,55+127,72+247,34)$ & 450,62 \\
& Average & $(24,64+23,20+63,05)$ & 110,89 \\
LVe5 & Min. & $(2,02+4,25+10,89)$ & 17,17 \\
& Max. & $(71,76+91,48+214,97)$ & 378,22 \\
& Average & $(29,56+23,26+59,36)$ & 112,18 \\
& Min. & $(2,40+3,70+8,94)$ & 15,04 \\
& Max. & $(87,56+88,67+202,64)$ & 378,87 \\
\hline
\end{tabular}

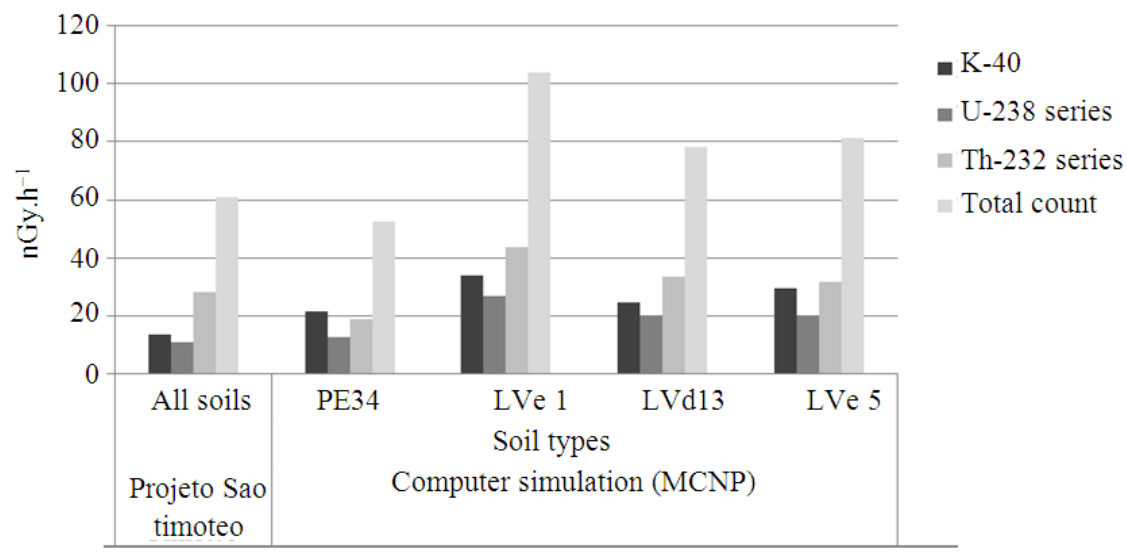

Fig. 4. Comparison of external gamma exposure between the Projeto São Timóteo (total area) and computer simulation results for each soil type in the area of the Uraniferous Province of Lagoa Real

\section{DISCUSSION}

The soil type LVel showed the highest average value (34 nGy.h ${ }^{-1}$ ) due to ${ }^{40} \mathrm{~K}$ as shown in Table 4 . Maruejol et al. (1987) reports a high concentration of potassium in the soil of the Province of Lagoa Real and described a removal of potassium rocks of the province during a geochemical process known as sodium metasomatism, where potassium has been largely replaced from the rock and thus triggered their increased concentration in the surface. The dispersion between the minimum and maximum of air Kerma rate due to ${ }^{40} \mathrm{~K}$ and 
the soil types are also shown on Table $\mathbf{4}$ which are typical for radiometric measurements in areas with radioactive anomalies, because of the differences between the values mapped on the anomalies and the surrounding areas.

According to Saito and Jacob (1995), more than 90\% of the air Kerma rate of the ${ }^{238} \mathrm{U}$ series originates from the contribution of two radionuclides only, ${ }^{214} \mathrm{Bi}$ and ${ }^{214} \mathrm{~Pb}$ which is confirmed by this study. As shown in Table 5, the largest contribution from the ${ }^{238} \mathrm{U}$ series is due to the ${ }^{214} \mathrm{Bi}(\sim 85 \%)$ and secondarily due to the ${ }^{214} \mathrm{~Pb}$ $(\sim 12 \%)$, considering the average values for all soil types. This explains why, for example, the photon energy of $1.76 \mathrm{MeV}$ of ${ }^{214} \mathrm{Bi}$ can be used as reference for detecting the spectrum channel tracking uranium.

The values of the air Kerma rate shown in Table 4 and 5 are highly dependent on the variation of the concentration values shown in Table 2, following the trend of their behavior in each type of soil, which implies higher values for soil type LVe1 and lower to the soil type PE34.

Regarding the ${ }^{232} \mathrm{Th}$ series, as shown in Table 6, it is estimated that the radionuclides ${ }^{228} \mathrm{Ac}$ and ${ }^{208} \mathrm{Tl}$ contribute with about $90 \%$ and radionuclides ${ }^{212} \mathrm{~Pb}$ and ${ }^{212} \mathrm{Bi}$ with about $9 \%$ to the total air Kerma. These data is also in agreement with the results presented by Saito and Jacob (1995) for this series. It explains the reason why the $2.6 \mathrm{MeV}$ gamma energy of the ${ }^{208} \mathrm{Tl}$ can be used as reference for the screening of thorium. In the simulations proposed, the photons due to ${ }^{228} \mathrm{Ra}$ decay were completely attenuated in the path source-detector and that is the reason why its contribution was nearly zero. Considering the average values, the results for air Kerma rates for the ${ }^{232} \mathrm{Th}$ series, as shown in Table 6, are higher for soil type LVe1 followed by types LVd13 and LVe5, showing very close values and type PE34 as the soil with lowest values.

LVd13 and LVe5, showing very close values and type PE34 as the soil with lowest values.

Kerma rates for the ${ }^{232}$ Thseries, as shown in Table 6, are higher for soil type LVe1 followed by types LVd13 and LVe5, showing very close values and type PE34 as the soil with lowest values.

proposed, the photons due to ${ }^{228} \mathrm{Ra}$ decay were completely attenuated in the path source-detector and that is the reason why its contribution was nearly zero. Considering the average values, the results for air Kerma rates for the ${ }^{232}$ Thseries, as shown in Table 6, are higher for soil type LVe1 followed by types LVd13 and LVe5, showing very close values and type PE34 as the soil with lowest values.
As shown in Table 7, the estimated contribution of ${ }^{40} \mathrm{~K},{ }^{232} \mathrm{Th}$ and ${ }^{238} \mathrm{U}$ series for the outdoor air Kerma rate ranged, on average, from $70.78 \mathrm{nGy} \cdot \mathrm{h}^{-1}$, for soil type PE34, to $146.40 \mathrm{nGy}^{-1}$, for soil type LVe1, which is the world estimated average for air Kerma rate for outdoor environments. Considering the contribution of ${ }^{40} \mathrm{~K},{ }^{232} \mathrm{Th}$ and ${ }^{238} \mathrm{U}$ series, the maximum value of air Kerma rate was found to be $450.62 \mathrm{nGy} \cdot \mathrm{h}^{-1}$, for soil type LVe1 and the lowest value to be $7 \mathrm{nGy} \cdot \mathrm{h}^{-1}$, for soil type $\mathrm{PE} 34$.The contribution of the background radiation is 59 nGy. $\mathrm{h}^{-1}$, varying from country to country in the range of $18 \mathrm{nGy} \cdot \mathrm{h}^{-1}$ to $93 \mathrm{nGy} \cdot \mathrm{h}^{-1}$ (UNSCEAR, 2000).

In percentage terms, the ${ }^{40} \mathrm{~K}$ contributes about $30 \%$ (soil type PE34), ${ }^{232} \mathrm{Th}$ series contributes, at most, about 58\% (soil types $\mathrm{LVe} 1$ and $\mathrm{LVd} 13$ ) and ${ }^{238} \mathrm{U}$ series on average about $20 \%$ (soil types PE34, LVe1, LVd13 and LVe5) to the total air Kerma rate in each type of studied soils.

The gamma rays due to the ${ }^{235} \mathrm{U}$ series contribute very little to the gamma ray field at the ground surface in natural environment. Uranium in nature is distributed around $0.7 \%$ of ${ }^{235} \mathrm{U}$ and about $99.3 \%$ of ${ }^{238} \mathrm{U}$ and hence the series of the latter is much more relevant for assessing the radiological risk.

\section{CONCLUSION}

This study aims de evaluation of soil type and air Kerma above ground in the Province of Lagoa Real located Brazil based on the data originated from aerial survey of the Projeto São Timóteo project.

As expected, he levels of natural radionuclides are directly linked to the content of silica in rocks and soils, confirming the pattern determined by IAEA (2003) and Dickson and Scott (1997). Therefore, regions rich in silica exhibit radiometric measurements with higher values. Furthermore, regions derived from basic and ultra-basic rocks have lower levels of radionuclides and, consequently, lower levels of radiometric measurements.

Soil type LVe1, which is rich in silica, presents higher values of air Kerma for ${ }^{40} \mathrm{~K}$ ( $34 \mathrm{nGy} \cdot \mathrm{h}^{-1}$ average) and the radioactive series of ${ }^{238} \mathrm{U}\left(30,77 \mathrm{nGy} \cdot \mathrm{h}^{-1}\right.$ average $)$ and ${ }^{232} \mathrm{Th}\left(81,64 \mathrm{nGy} \cdot \mathrm{h}^{-1}\right.$ average), while soil type PE34, which is derived from basic and ultra-basic rocks present the lower values of air Kerma for ${ }^{40} \mathrm{~K}\left(21,35 \mathrm{nGy} \cdot \mathrm{h}^{-}\right.$ ${ }^{1}$ average $)$ and the radioactive series of ${ }^{238} \mathrm{U}\left(14,36 \mathrm{nGy} \cdot \mathrm{h}^{-1}\right.$ average) and ${ }^{232} \mathrm{Th}\left(35,07 \mathrm{nGy} \cdot \mathrm{h}^{-1}\right.$ average).

The simulation results also reflected the behavior of external gamma exposure data of airborne gamma-ray survey previously conducted in the region of the province as shown in Fig. 4. It also shows the greater 
contribution of ${ }^{232} \mathrm{Th}$ series, present in higher concentrations than the ${ }^{238} \mathrm{U}$ series and the sodium metasomatism event that occurred in the province increased the surface contribution of ${ }^{40} \mathrm{~K}$.

\section{ACKNOWLEDGEMENT}

Special thanks to DIMAP/CNEN for allowing the use of the data from the Projeto São Timóteo for this study.

\section{REFERENCES}

Clouvas, A., S. Xanthos, M. Antonopoulos-Domis and J. Silva, 2000. Monte carlo calculation of dose rate conversion factors for external exposure to photon emitters in soil. Health Phys., 78: 295-302. DOI: 10.1097/00004032-200003000-00007

Conti, C.C., L. Bertelli and R.T. Lopes, 1999. Agedependent dose in organs per unit air Kerma free-inair: Conversion coefficients for environmental exposure. Radiat. Prot. Dosim., 86: 39-44. DOI: 10.1093/oxfordjournals.rpd.a032923

Dickson, B.L. and K.M. Scott, 1997. Interpretation of aerial gamma-ray surveys-adding the geochemical factors. AGSO J. Aust. Geol. Geophys., 17: 187200.

Eckerman, K.F. and J.C. Ryman, 1993. External Exposure to Radionuclides in Air, Water and Soil. 1st Edn., U.S. EPA., Washington, D.C., pp: 235.

EMBRAPA, 1979. Levantamento exploratorioreconhecimento de solos da margem direita do Rio Sao Francisco, estado da Bahia. Recife.

IAEA, 2003. Guidelines for Radioelement Mapping Using Gamma RAY Spectrometry Data. 1st Edn., Renouf Publishing Company Limited, Vienna, ISBN-10: 9201083033, pp: 173.

ICRUM, 1980. Radiation Quantities and Units. 1st Edn., ICRUM, Washington, pp: 25.

Jacob, P. and H.G. Paretzke, 1987. Dose-rate conversion factors for external gamma exposure. Nucl. Instrum. Methods Phys. Res. A., 255: 156-159. DOI: 10.1016/0168-9002(87)91092-8
LANL, 2003. MCNP. A general Monte Carlo n-Particle Transport Code. Overview Theory.

Lobato, L.M., J.M.A. Forman, K. Fuzikawa, W.S. Fyfe and R. Kerrich, 1982. Uranium enrichment in Archean basement: Lagoa Real, Brazil. Soc. Br. Geol., 12: 484-486.

Maruejol, P., M. Cuney, K. Fuzikawa, A.M. Netto and B. Poty, 1987. The Lagoa Real subalkaline granitic complex (South Bahia, Brazil): A source for uraniun mineralizations associated with $\mathrm{Na}-\mathrm{Ca}$ metassomatism. Revista Brasileira Geociencias, 17: 578-594.

Meckbach, R., I.K. Bailiff, Y. Goksu, P. Jacob and D. Stoneham, 1996. Calculation and measurement of depth dose distributions in bricks. Radiat. Prot. Dosim., 66: 183-186. DOI: 10.1093/oxfordjournals.rpd.a031712

Nowotny, R., 1998. XMUDAT: Photon attenuation data on PC. IAEA, Vienna.

Saito, K. and P. Jacob, 1995. Gamma ray fields in the air due to sources in the ground. Radiat. Prot. Dosim., 58: 29-45.

Salinas, I.C.P., C.C.C. Conti and R.T. Lopes, 2006a. Effective density and mass attenuation coefficient for building material in Brazil. Appl. Radiat. Isotopes, $\quad 64$ : 13-18. DOI: 10.1016/j.apradiso.2005.07.003

Salinas, I.C.P., C.C.C. Conti and R.T. Lopes, 2006 b. Gamma shielding factor for typical houses in Brazil. Radiat. Prot. Dosim., 121: 420-424. DOI: 10.1093/rpd/ncl075

Salinas, I.C.P., C.C.C. Conti and R.T. Lopes, 2007. Effect of windows and doors on the gamma shielding factor for typical houses in Brazil. Health Phys., 92: 251-256. DOI: 10.1097/01.HP.0000250798.99581.00

UNSCEAR, 2000. Sources and Effects of Ionizing Radiation. 1st Edn., United Nations Publications, New York, ISBN-10: 9211422388, pp: 654. 